\title{
Dual-Ioop Primary Frequency Regulation Controller for VSC-HVDC System
}

DOI:

10.1109/PTC.2017.7980808

\section{Document Version}

Accepted author manuscript

Link to publication record in Manchester Research Explorer

\section{Citation for published version (APA):}

Shah, R., Preece, R., \& Barnes, M. (2017). Dual-loop Primary Frequency Regulation Controller for VSC-HVDC System. In 12th IEEE PES PowerTech Conference (pp. 1-6). IEEE. https://doi.org/10.1109/PTC.2017.7980808

\section{Published in:}

12th IEEE PES PowerTech Conference

\section{Citing this paper}

Please note that where the full-text provided on Manchester Research Explorer is the Author Accepted Manuscript or Proof version this may differ from the final Published version. If citing, it is advised that you check and use the publisher's definitive version.

\section{General rights}

Copyright and moral rights for the publications made accessible in the Research Explorer are retained by the authors and/or other copyright owners and it is a condition of accessing publications that users recognise and abide by the legal requirements associated with these rights.

\section{Takedown policy}

If you believe that this document breaches copyright please refer to the University of Manchester's Takedown Procedures [http://man.ac.uk/04Y6Bo] or contact uml.scholarlycommunications@manchester.ac.uk providing relevant details, so we can investigate your claim.

\section{OPEN ACCESS}




\title{
Dual-loop Primary Frequency Regulation Controller for VSC-HVDC System
}

\author{
Rakibuzzaman Shah, Robin Preece, and Mike Barnes \\ School of Electrical and Electronic Engineering \\ The University of Manchester, M13 9PL \\ Manchester, United Kingdom \\ E-mail: rakibuzzaman.shah@manchester.ac.uk; robin.preece@manchester.ac.uk; mike.barnes@manchester.ac.uk
}

\begin{abstract}
This paper presents a frequency control mechanism for an AC system through the active and reactive power loops of a VSC-HVDC system. The proposed scheme makes use of the reactive power loop for inertia support by exploiting the voltagepower sensitivity of loads, and active power droop control has been used to provide governor-like support following the largedisturbance. The performance of the presented controller is evaluated through various simulation case studies in DIgSILENT Power Factory including small-perturbation to demonstrate the effect of the frequency controller in system electromechanical mode damping. From the set of case studies it can be found that the proposed dual-loop control has favorable effects on the frequency behaviour and the inter-area mode damping of the system.
\end{abstract}

Index Terms-Droop control, frequency stability, inertia control, primary frequency control.

\section{INTRODUCTION}

The frequency stability of a power system refers to the ability of the system to maintain the frequency within acceptable limits following a large-disturbance which may or may not divide the system into subsystems [1]. A significant deviation of the frequency from its nominal value will typically occur following a large-disturbance in the system. In conventional systems with large numbers of synchronous generators, the conventional generator rotating mass, i.e. rotating inertia, releases the kinetic energy (KE) stored in its rotating mass to meet any short discrepancies between the mechanical power from the turbine and the electrical consumption of the system loads. The system inertia determines the rate at which the frequency changes for a given disturbance, providing time for the stabilizing governor action. High penetrations of HVDC interconnections and offshore wind power plants (WPPs) through HVDC links are (in some networks) displacing conventional synchronous generators. This results in a drastic reduction of the effective system inertia. The possibility of large and more frequent infeed losses in a reduced inertia system is likely to cause a large variation of frequency and a higher rate of change of frequency (RoCoF). Thus, there is a growing interest in utilizing the VSC-HVDC control flexibility to help support the frequency regulation of the system. The recently published network code for VSC-HVDC connections by the European Network of Transmission System Operators for Electricity (ENTSO-E) has mandated that VSC-HVDC links should provide frequency support to main grids [2].

The general capability of a VSC-HVDC supplementary controller for power system frequency stability enhancement has been reported in several papers [3]-[7]. It has been proposed that VSC-HVDC system participates in frequency control through a supplementary frequency control loop in the active power or direct voltage loop [3]-[7]. Research work in [3] and [4] has reported a classical frequency droop controller for the frequency control through a VSC-HVDC link. Work in [5] has explored the droop gain modification based frequency control of VSC-HVDC for the AC system frequency support. Effects of feedback signals and the delay associated with feedback signals are assessed. A small deadband and filter are proposed in [5] to limit the frequency oscillation under normal operation. A standard synthetic inertia controller using the frequency derivative is proposed in [6]. An integrated synthetic inertia emulation controller using the DC voltage control loop is proposed in [7]. However, the DC-link considered in [7] was an ideal DC source with large energy storage capacity, which is yet to be commercially available.

The previously cited work dealt to a great extent regarding the frequency support through VSC-HVDC, however, room for further research still exists. A droop control introduced in a VSC-HVDC system extracts the power from the connected WPP to emulate the governor type behaviour of a synchronous generator. However, this is limited by the WPP rating and operating conditions. Moreover, a large droop value improves the frequency stability of the system, but may adversely affect the DC link stability of the VSC-HVDC system. Furthermore, the droop method improves the steady-state frequency behaviour of the system rather than the transient condition. Instead, inertia control has been utilized to improve the transient frequency behaviour. The performance of an inertia response controller implemented within the DC voltage or active power loop depends on the DC link capacitor size. Therefore, an alternative approach for adding virtual inertia to the system is 
required. The concept of adding a frequency controller to the system through the exciter control of synchronous generators has been proposed in [8], [9]. However, the utilization of VSC-HVDC reactive power control loop for adding a virtual inertia is yet to be explored.

Although the technical performance of the frequency response support from VSC-HVDC has widely been studied, its impacts on system electromechanical (EM) modes are not yet fully understood. As reported in [10], the primary frequency control of VSC-HVDC can have a significant impact on the damping of inter-area modes in power systems. However, the numerical analysis conducted in [10] is based on a derivative based frequency controller for an active power loop with a number of assumptions (i.e. simplification of $\mathrm{AC}$ grid controllers). Besides, the analysis has been carried out with a limited number of operating scenarios. Motivated by the aforementioned knowledge gaps the main aims of this paper are as follows:

I. To explore an alternative structure of frequency support control for VSC-HVDC.

II. To investigate the influence of the proposed VSCHVDC frequency provision control on the EM modes of the system under multiple operating scenarios.

The paper structured as follows: Section II illustrates the frequency control overview including the proposed controller. Section III presents the test network used in this paper. Simulation results and discussion are given in Section IV. Conclusions are duly made in Section V.

\section{FREQUENCY CONTROL OVERVIEW}

\section{A. Key Terminologies}

In a power system under the steady-state condition, the total generated power is always equal to the system load plus losses. The frequency of the system is a global variable by which the generation-demand mismatch is observable throughout the entire grid. For the reliable and efficient operation of the power system, the frequency of the system must be kept constant. A number of control actions are usually applied in different time frames to keep the system frequency constant, as given in Table I [11].

TABLE I. FREQUENCY CONTROL BAND [11]

\begin{tabular}{|ccc|}
\hline Control & Ancillary service & Time-frame \\
\hline Primary control & Frequency response & $10-60 \mathrm{~s}$ \\
\hline Secondary control & Regulation & $1-10$ mins \\
\hline Tertiary control & Imbalance/reserves & 10 mins-hours \\
\hline Time control & Time error correction & Hours \\
\hline
\end{tabular}

The rows in Table I correspond to the classification of how different control actions should respond and the appropriate time-frame for the respective control action to minimize the mismatch between the generation and demand. This particular paper addresses the use of VSC-HVDC link to supplement primary frequency control (or frequency containment). The frequency response characteristics of the system are briefly described in this section. Fig. 1 shows a typical response of the primary frequency control of power systems following a large-disturbance. The key indicators of frequency response characteristics are defined next.

Rate of Change of Frequency (RoCoF): RoCoF is a factor that describes how fast the frequency changes following a large-disturbance (at A in Fig. 1). This should not be above certain limits as fast decelerations may be deleterious for generators. The maximum allowable RoCoF depends on the operation requirements and grid codes of respective transmission system operators (TSOs).

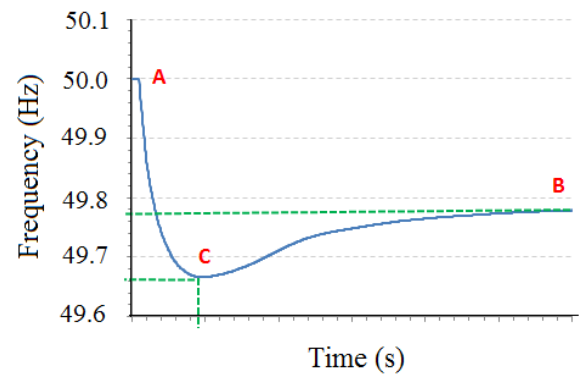

Figure 1. Typical power system frequency response including primary control.

According to the grid code from the Great Britain (GB) Transmission System Operator, National Grid Electricity Transmission plc, the maximum allowable RoCoF is currently $0.125 \mathrm{~Hz} / \mathrm{s}$. The maximum allowable RoCoF for the GB system will be increased to $0.5 \mathrm{~Hz} / \mathrm{s}$ by the end of 2016 in a move to align the grid codes with the anticipated reduction in system inertia [12]. The RoCoF can be approximated by (1) $[13]$ :

$$
R o C o F=\frac{1}{2} \frac{\Delta P}{I R} \times f_{0}
$$

In (1), $\Delta P$ is the power mismatch between generation and demand (MW), $I R$ denotes the inertia response of the system (MWs), and $f_{0}$ is the nominal frequency $(\mathrm{Hz})$. The inertia response of the system can be defined as (2):

$$
I R=\sum_{i=1}^{i=n}\left(S_{i} \times H_{i}\right)
$$

In (2), $S_{i}$ refers the rated MVA of $i^{\text {th }}$ synchronous generator and $H_{i}$ denotes the inertia constant (s) of $i^{\text {th }}$ synchronous generator. In practice, synchronous motor loads will also provide system inertia, however, these are often neglected from such studies.

Frequency Nadir: Frequency nadir is the maximum frequency excursion, before the frequency decline is arrested, which can be determined by the frequency difference between points $\mathrm{A}$ and $\mathrm{C}$ in Fig. 1. The frequency nadir is a direct measure of the adequacy of primary frequency control [13]. A frequency nadir higher than the threshold point of under frequency load shedding means there is an adequate primary frequency reserve in the system, whereas, a frequency nadir lower than the threshold point of under frequency load shedding translates to an inadequacy of the system primary frequency reserve [13].

This study focuses on the broad systematic issue of the frequency stability of the system. Measuring frequency at 
specific nodes or tie-lines of the system following a largedisturbance may be misleading and confusing. Thus, to clearly show the frequency behaviour of the system, the expression of the equivalent system frequency as in (3) has been utilized in this work [13].

$$
f_{e q}=\frac{\sum_{i=1}^{n} S_{i} \times f_{i} \times H_{i}}{\sum_{i=1}^{n} S_{i} \times H_{i}}(\mathrm{~Hz})
$$

In (3), $S_{i}$ is the MVA rating of the $i^{\text {th }}$ generator, $H_{i}$ is the inertia of the $i^{\text {th }}$ generator, and $f_{i}$ is the frequency of the $i^{\text {th }}$ generator.

Settling Frequency: The settling frequency refers to the frequency at which the primary frequency control is stabilized [13]. In Fig. 1, point B presents the settling frequency.

\section{B. Modified VSC-HVDC Frequency Controller}

A number of different frequency regulation techniques have been proposed for the VSC-HVDC system. These methods can broadly be classified into three: (1) droop based method, (2) inertia emulation or virtual inertia, and (3) a combination of droop and inertia. Additionally, the recent development in reactive power (Q) based frequency regulation opens up the possibility to use inertia emulation in the Q loop of the VSC-HVDC system. In this paper, the VSC-HVDC frequency control structure given in Fig. 2 has been investigated under various system operating conditions.

The main concept is to build an additional VSC-HVDC frequency control on top of the state-of-the-art frequency control approach (in this case droop control) to provide virtual reserve through VSC-HVDC systems. The frequency control structure given in Fig. 2 provides a governor like droop behaviour through active power (P) or DC voltage loop, henceforth referred as droop at $P$ loop. The virtual inertia is provided through the reactive power or AC voltage control loop of the VSC-HVDC system, henceforth referred as inertia at $Q$. Appropriate filters (i.e. low pass filter) and limiters are used in both loops to avoid the undesirable control operation.

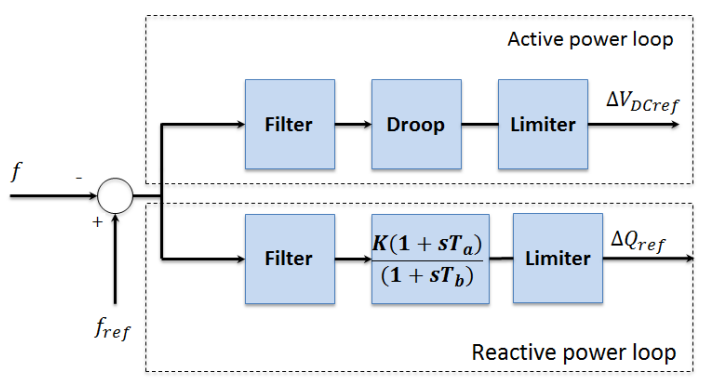

Figure 2. Modified VSC-HVDC frequency controller.

The droop controller exploits the WPP active power to provide a frequency regulation service to the host AC system. Since the frequency droop control in the DC voltage controller changes the DC voltage of the entire link, utilization of this could potentially provide a means by which a decoupled WPP can be informed the occurrence of the frequency event in the AC system. Frequency droop and a transient frequency adjustment as a function of DC link voltage is used to configure the offshore VSC system to contribute to the offshore grid frequency control with other converters. The $\pm 10 \%$ limit of DC voltage has been chosen for the active power loop control whereas, $\pm 25 \%$ limit of reactive power has been chosen for the reactive power loop control. Table II gives the parameters of the frequency controller. The frequency control parameters are selected based on the sensitivity study of the frequency regulation mode.

TABLE II. FREQUENCY CONTROLLER PARAMETERS

\begin{tabular}{|cc|}
\hline Parameter & Value \\
\hline $\boldsymbol{k}$ & $2.0 \mathrm{pu}$ \\
\hline $\boldsymbol{T}_{\boldsymbol{a}}$ & $0.5 \mathrm{~s}$ \\
\hline $\boldsymbol{T}_{\boldsymbol{b}}$ & $3.6 \mathrm{~s}$ \\
\hline
\end{tabular}

\section{TEST NETWORK}

The test system used in this work is based on the generic test system given in [14] with appropriate modifications. The structure and parameters of the system given in Fig. 3 (a) are selected such that the network is an approximation of the England and Scotland power system. Despite its simplicity, this network is a reasonable representation of the dynamic frequency behaviour of the UK system. As given in the figure, the system consists of three representative generators in the England and Scotland power system. Since the voltage-power sensitivity of the loads is exploited here for the inertia support, it is, therefore, important to use appropriate load models in the aggregated load at bus 3 and 6 . The dynamic simulation has been conducted in this paper using a polynomial load model and the sensitivity of the results to this model is explored further in Section IV. An aggregated round rotor synchronous generator is considered to represent the each generator of the system. All three generators are equipped with a DC1A excitation system and steam governor as well as local PSS.

The offshore AC system is developed to represent the offshore WPPs and the interconnections. The system consists of eight aggregated full converter wind turbines with a total capacity of $1500 \mathrm{MW}$ as given in Fig. 3 (b). As shown in Fig. 3 (b), 33/220 kV three winding transformers connect each two of the wind turbines at the low voltage side of four $220 / 325 \mathrm{kV}$ step-up transformers. The wind turbines are integrated to the onshore AC system at bus 4 by two parallel VSC-HVDC links. Each converter terminal in the system is rated at $1000 \mathrm{MW}, \pm 320 \mathrm{kV}$ with the $\mathrm{DC}$ capacitor of $150 \mu \mathrm{F}$. The two VSC-HVDC links are connected offshore on the AC side by a $10 \mathrm{~km}$ cable to form an offshore grid. A DC chopper is used on the grid-side of the converters to facilitate the onshore fault-ride through. The system is modelled in DIgSILENT Power Factory 15.2 [15].

\section{Simulation StUdies}

\section{A. Under Frequency Event}

Fig. 4 shows the simulation results of the system frequency responses with different controllers installed. An 
outage of generator 2 (a $1700 \mathrm{MW}$ in-feed loss) in the UK equivalent system has been used to initiate the under frequency phenomena in the system. The equivalent frequency of the system previously defined in (3) is shown in Fig. 4. It can be observed that the frequency drop is significantly reduced for the dual-loop controller.

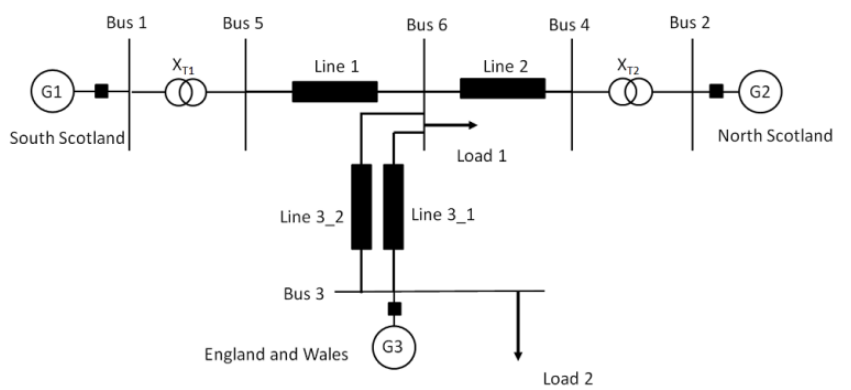

(a)

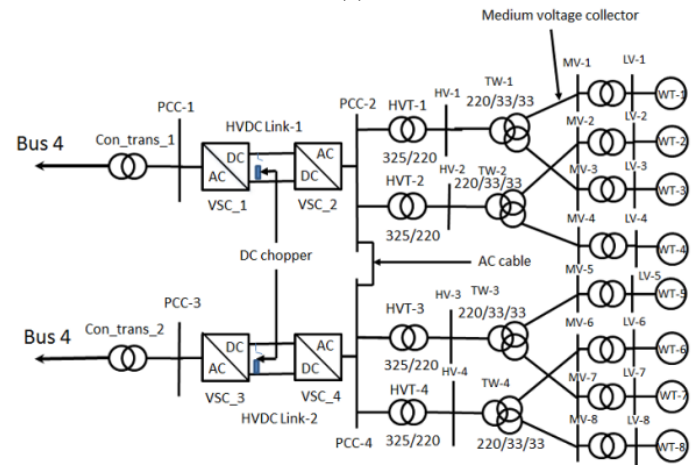

(b)

Figure 3. Test system model: (a) Three-machine UK equivalent test system; (b) HVDC link and offshore AC system.

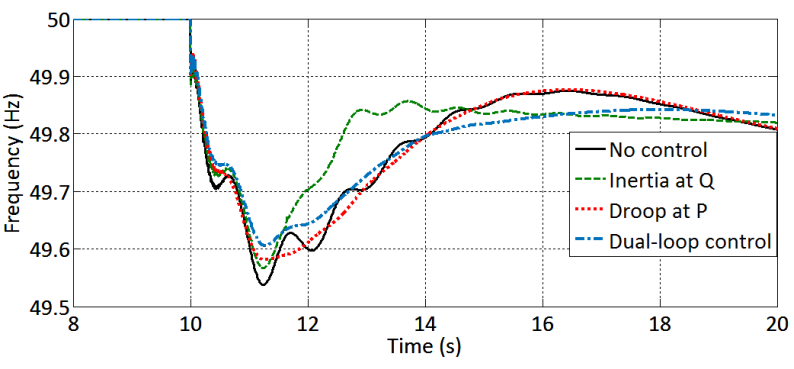

Figure 4. System frequency.

Table III gives the frequency nadir simulation results for an under frequency event in the system. From Table III, it can be seen that the dual-loop frequency support control within the VSC-HVDC system reduces the frequency dip significantly as compared to the droop at $\mathrm{P}$ and virtual inertia at $\mathrm{Q}$ control loop. Table III also gives the RoCoF of the system for the outage of $1700 \mathrm{MW}$ in-feed (i.e. outage of generator 2). The RoCoF values are calculated numerically using a $100 \mathrm{~ms}$ measurement window as reported in [16]. From the results in Table III, it can be observed that the $\mathrm{RoCoF}$ of the system is reduced considerably with the implementation of the dual-loop frequency support control within the VSC-HVDC system.

The deviations of load active power with and without the proposed controller are given in Fig. 5. Following the large- disturbance, a change of $265 \mathrm{MW}$ of active power demand can be achieved with the proposed control action. The impact of the proposed controller on DC link voltage compared to the droop at $\mathrm{P}$ and virtual inertia at $\mathrm{Q}$ control loop is given in Fig. 6. From the results in Fig. 6, it is evident that the dual control exhibits a lower DC voltage excursion as compared to the droop control with much better frequency response than the droop control. This is because, in the dual control, the droop gain has been reduced. From the figure, it can be seen that for the virtual inertia at Q loop, the DC voltage response of the system displays the similar trends as of the VSCHVDC system without frequency controller.

TABLE III. FREQUENCY RESPONSE DURING UNDERFREQUENCY EVENT

\begin{tabular}{|ccc|}
\hline Controller & Frequency nadir $(\mathbf{H z})$ & RoCoF $(\mathbf{H z} / \mathbf{s})$ \\
\hline No control & 49.53 & -0.86 \\
\hline Inertia at $\mathbf{Q}$ & 49.58 & -0.55 \\
\hline Droop at $\mathbf{P}$ & 49.59 & -0.51 \\
\hline Dual-loop control & 49.62 & -0.40 \\
\hline
\end{tabular}

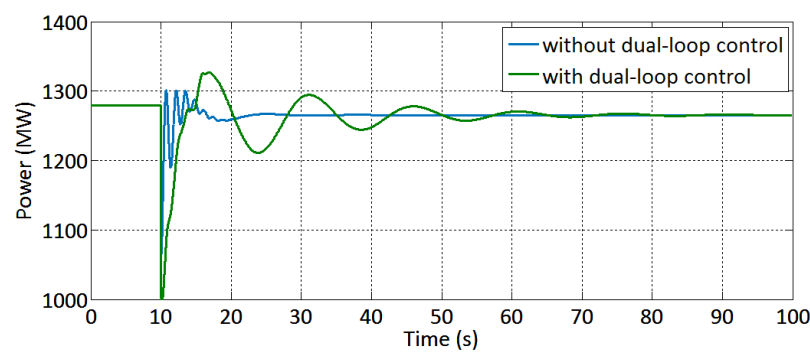

Figure 5. Load power variations at bus 6 .

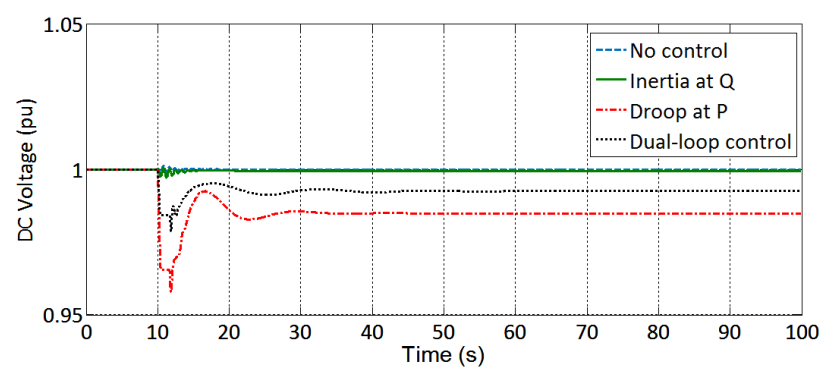

Figure 6. DC voltage responses following the underfrequency event.

\section{B. Over Frequency Event}

An outage of the load at bus 6 has been used to trigger the over frequency phenomena of the system. The outage of 1320 MW power in the system results in the frequency to be over the acceptable upper limit $(50.2 \mathrm{~Hz})$ of the nominal operation, as given in Table IV. From Table IV, it can be seen that the dual-loop frequency control support provided through the VSC-HVDC could claim to outperform the frequency controller at $\mathrm{P}$ and $\mathrm{Q}$ loop in terms of the peak frequency reduction following an outage of the load at bus 6 . Comparably, the separate support provided by the droop control through $\mathrm{P}$ and virtual inertia control at $\mathrm{Q}$ also lowers the peak frequency. The RoCoF value during the over frequency event is also reduced with the dual-loop control within the VSC-HVDC link. 
TABLE IV. FREQUENCY RESPONSE DURING OVER FREQUENCY EVENT

\begin{tabular}{|ccc|}
\hline Controller & Over Frequency $(\mathbf{H z})$ & RoCoF $(\mathbf{H z} / \mathbf{s})$ \\
\hline No control & 50.30 & 0.61 \\
\hline Inertia at $\mathbf{Q}$ & 50.29 & 0.52 \\
\hline Droop at $\mathbf{P}$ & 50.28 & 0.48 \\
\hline Dual-loop control & 50.27 & 0.45 \\
\hline
\end{tabular}

\section{Effect of Load Model}

The frequency regulation through the Q loop depends on the active power demand sensitivity to the voltage regulation in the system. Hence, it is important to assess the frequency responses of the system for different load models. The active power demand sensitivity of the load to the operating voltage is determined by the voltage index in the load model. Thus, a variation in the voltage index (i.e. variation of load arrangement) changes the sensitivity of the active power demand to the voltage, and therefore affects the performance of the frequency regulation through the Q loop. Table V lists the frequency nadir and RoCoF indices of the system for different load arrangements with the proposed frequency regulation control. The corresponding parameters of the load models listed in Table $\mathrm{V}$ are given in Appendix. There is always a possibility that load compositions different from these may encounter in practice - they are simply models after all. However, the load compositions in Table $\mathrm{V}$ are used as the probable possibilities to assess the effectiveness of the proposed frequency controller [17].

From the results in Table V, it can be seen that the system experienced the lowest RoCoF $(0.4049 \mathrm{~Hz} / \mathrm{s})$ when a constant impedance $(Z)$ load model is applied to the system. In contrast, the system experienced the largest $\mathrm{RoCoF}(0.427 \mathrm{~Hz} / \mathrm{s})$ when the exponential load 2 model is applied to the system. The voltage index in exponential load 2 is smaller compared to the other load compositions given in Table V. Therefore, this reduces the active power demand sensitivity to the operating voltage and results in a higher RoCoF for the system. From the results in Table $\mathrm{V}$, it is also worth noting that the frequency nadir of the system is also changed with load compositions for the proposed frequency controller. However, the discrepancies of frequency nadir for various load compositions are small.

TABLE V. FREQUENCY RESPONSE COMPARISON FOR DIFFERENT LOAD MODELS

\begin{tabular}{|ccc|}
\hline Load model & Frequency nadir $(\mathbf{H z})$ & RoCoF $(\mathrm{Hz} / \mathbf{s})$ \\
\hline $\begin{array}{c}\text { Active power: } \mathbf{Z I P} ; \\
\text { Reactive power: } \mathbf{Z I P}\end{array}$ & 49.605 & 0.4070 \\
\hline $\begin{array}{c}\text { Active power: } \mathbf{I} ; \\
\text { Reactive power: } \mathbf{I}\end{array}$ & 49.605 & 0.4105 \\
\hline $\begin{array}{c}\text { Active power: } \mathbf{Z} ; \\
\text { Reactive power: } \mathbf{Z}\end{array}$ & 49.601 & 0.4049 \\
\hline Exponential load $\mathbf{1}$ & 49.605 & 0.4093 \\
\hline Exponential load 2 & 49.608 & 0.4270 \\
\hline $\mathbf{Z}=$ constant impedance; $\mathbf{I}=$ constant current; $\mathbf{P}=$ constant power
\end{tabular}

D. Impact on Electromechanical Modes

The aim of this study is to investigate the UK threemachine equivalent model electromechanical (EM) modes under the effect of the supplementary frequency regulation controller as described in Section II. B. The analysis has been conducted under various operating conditions including different DC link power flow and varying generation scenarios. DC link powers shown in Table VI are chosen to represent the 0 to $75 \%$ production of wind power. The loading of generator 3 has been changed to portrait the tieline flow changes in between bus 3 and 6 . The damping $(\zeta)$ and frequency $(f)$ of the EM modes are listed in Table VI for various power flow conditions in DC links. The damping of mode 1 and 2 without the proposed frequency regulation control is $9.2 \%$ (inter-area) and $6.17 \%$ (local mode), respectively. From the results in Table VI, it can be seen that the damping of the inter-area mode improves significantly with the proposed controller. Moreover, the inter-area mode damping increases with the DC link power when the proposed frequency controller is employed. According to the results in Table VI, it can be seen that the proposed controller has an adverse effect on the damping of the mode 2 (local mode), reducing the damping below the typically used 5\% threshold. The damping of mode 2 decreases with DC link power when the proposed frequency controller is employed within the VSC-HVDC system.

Table VII illustrates the percentage damping factor and frequency (in $\mathrm{Hz}$ ) of the EM modes for various loading conditions of generator $1(\mathrm{G} 1)$ and generator $2(\mathrm{G} 2)$ (see Fig. 3 (a)). G1 and G2 loading is varied from $100 \%$ to $65 \%$ for this scenario. From the results in Table VII, it can be seen that the damping of the inter-area mode remains within the vicinity of $15 \%$ damping in all cases. Furthermore, the damping of the local mode varies within the range of $4.40 \%$ to $5.0 \%$ for various loading of G1 and G2 in the system.

TABLE VI. EM MODES FOR DC LINK POWER CHANGES

\begin{tabular}{|c|c|c|cc|}
\multirow{2}{*}{ DC link power } & \multicolumn{2}{|c|}{ Mode 1 } & \multicolumn{2}{c|}{ Mode 2 } \\
\cline { 2 - 5 } & $\xi \%$ & $\boldsymbol{f}(\boldsymbol{H z})$ & $\xi \%$ & $\boldsymbol{f}(\boldsymbol{H z})$ \\
\hline $\mathbf{0 . 0} \mathbf{M W}$ & 13.00 & 0.80 & 4.63 & 1.58 \\
\hline $\mathbf{3 8 0} \mathbf{M W}$ & 15.40 & 0.79 & 4.40 & 1.57 \\
\hline $\mathbf{4 5 0} \mathbf{M W}$ & 15.88 & 0.78 & 4.37 & 1.57 \\
\hline $\mathbf{5 0 0}$ MW & 16.37 & 0.76 & 4.31 & 1.56 \\
\hline $\mathbf{5 5 0} \mathbf{M W}$ & 16.90 & 0.75 & 4.30 & 1.56 \\
\hline
\end{tabular}

TABLE VII. EM MODES FOR VARIOUS GENERATION SCENARIOS

\begin{tabular}{|c|ccc|c|c|}
\hline \multirow{2}{*}{$\begin{array}{c}\text { Generator Loading } \\
\text { (MW) }\end{array}$} & \multicolumn{2}{|c|}{ Mode 1 } & \multicolumn{2}{c|}{ Mode 2 } \\
\cline { 2 - 5 } G1: 1800 & $\xi \%$ & $\boldsymbol{f}(\boldsymbol{H z})$ & $\xi \%$ & $\boldsymbol{f}(\boldsymbol{H z})$ \\
\hline $\begin{array}{l}\text { G2: 1700 } \\
\text { G1: 1350 }\end{array}$ & 15.40 & 0.79 & 4.40 & 1.57 \\
\hline G2: 1700 & 15.02 & 0.82 & 4.52 & 1.58 \\
\hline $\begin{array}{l}\text { G1: 1800 } \\
\text { G2: 1250 }\end{array}$ & 14.62 & 0.82 & 4.91 & 1.59 \\
\hline $\begin{array}{l}\text { G1: 1250 } \\
\text { G2: 1700 }\end{array}$ & 14.51 & 0.82 & 5.00 & 1.59 \\
\hline $\begin{array}{l}\text { G1: 1800 } \\
\text { G2: 1150 }\end{array}$ & 15.00 & 0.81 & 4.53 & 1.57 \\
\hline
\end{tabular}

A non-linear simulation has been performed over a period of $20 \mathrm{~s}$ to further demonstrate the impact of the proposed frequency regulation controller on the inter-area mode of the 
system in the presence of non-linearity. The inter-area oscillation is initiated by a self-clearing three-phase fault at bus 6 for $80 \mathrm{~ms}$. Fig. 7 shows the power flow response of one of the tie-lines connecting bus 3 and 6 . It can be seen from the figure that the oscillation in the tie-line power flow is settled within $8 \mathrm{~s}$ with the proposed frequency regulation controller.

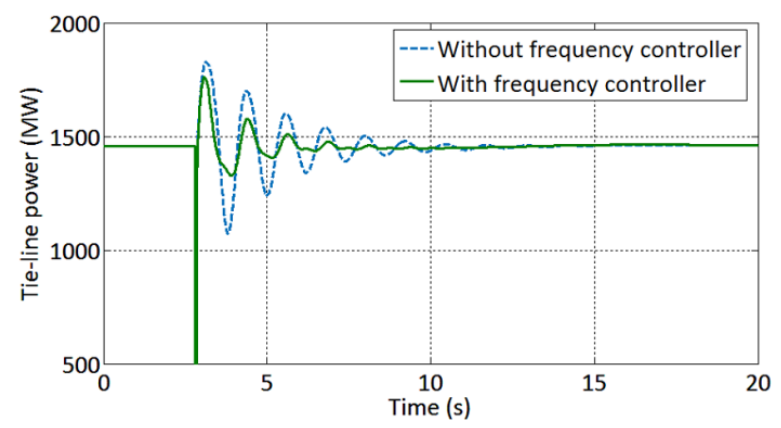

Figure 7. Tie-line power responses for a three-phase fault at bus 6 .

\section{CONCLUSIONS}

A systematic performance assessment of an alternative frequency control scheme for use with VSC-HVDC lines is presented in this paper. The dynamic behaviour of the system is provided based on the equivalent UK system. The dual-loop control strategy using the both $\mathrm{P}$ and Q loops of the HVDC control offers an attractive alternative to the previous strategies and a good trade-off between the performance and limitations. There are, however, some aspects of the system that must be carefully taken into consideration when designing a dual-loop frequency controller. The performance of the frequency regulation control at Q loop depends heavily on the load composition. Therefore, realistic load model parameters must be used to accurately assess the system performance. Moreover, the restrictive capability of the HVDC reactive power control to regulate the bus voltages in a large system may affect the frequency regulation performance of the system with the proposed controller. In such cases, a hierarchical voltage regulation control may be a suitable alternative for implementation within the VSC-HVDC system. The performance of such a hierarchical control scheme in a larger dynamic system with multi-terminal HVDC is the subject of ongoing research.

\section{APPENDIX}

TABLE VIII. LOAD MODEl PARAMETERS

\begin{tabular}{|c|c|c|}
\hline Load model & Load composition & Voltage index \\
\hline $\begin{array}{l}\text { Active power: ZIP; } \\
\text { Reactive power: ZIP }\end{array}$ & $\begin{array}{c}\mathrm{a}_{\mathrm{P}}=0.33 ; \mathrm{b}_{\mathrm{p}}=0.33 ; \mathrm{c}_{\mathrm{p}} \\
=0.33\end{array}$ & $\begin{array}{c}\mathrm{e}_{-} \mathrm{z}=2 ; \mathrm{e} \_\mathrm{I}=1 ; \\
\mathrm{e} \_\mathrm{P}=0.0\end{array}$ \\
\hline $\begin{array}{l}\text { Active power: I; } \\
\text { Reactive power: I }\end{array}$ & $\begin{array}{c}\mathrm{a}_{\mathrm{P}}=0.0 ; \mathrm{b}_{\mathrm{p}}=1.0 ; \mathrm{c}_{\mathrm{p}}= \\
0.0\end{array}$ & $\begin{array}{c}\mathrm{e}_{-} \mathrm{z}=2 ; \mathrm{e} \mathrm{I}=1 ; \\
\mathrm{e} \_\mathrm{P}=0.0\end{array}$ \\
\hline $\begin{array}{l}\text { Active power: } Z \text {; } \\
\text { Reactive power: } Z\end{array}$ & $\begin{array}{c}\mathrm{a}_{\mathrm{P}}=0.0 ; \mathrm{b}_{\mathrm{p}}=0.0 ; \mathrm{c}_{\mathrm{p}}= \\
1.0\end{array}$ & $\begin{array}{c}\text { e_z }=2 ; \mathrm{e}_{-} \mathrm{I}=1 ; \\
\mathrm{e} \_\mathrm{P}=0.0\end{array}$ \\
\hline Exponential load 1 & $\begin{array}{c}\mathrm{a}_{\mathrm{P}}=0.30 ; \mathrm{b}_{\mathrm{p}}=0.40 ; \mathrm{c}_{\mathrm{p}} \\
=0.30\end{array}$ & $\begin{array}{c}\mathrm{e} \_\mathrm{z}=2.1 ; \mathrm{e} \_\mathrm{I}=0.7 \\
\text { e_P }=0.7\end{array}$ \\
\hline Exponential load 2 & $\begin{array}{c}\mathrm{ap}_{\mathrm{p}}=0.30 ; \mathrm{b}_{\mathrm{p}}=0.40 ; \mathrm{c}_{\mathrm{p}} \\
=0.30\end{array}$ & $\begin{array}{c}\mathrm{e} \_\mathrm{z}=1.6 ; \mathrm{e} \_\mathrm{I} \\
=0.07 ; \mathrm{e} \mathrm{P}=0.07\end{array}$ \\
\hline
\end{tabular}

$\mathrm{Z}=$ constant impedance; $\mathrm{I}=$ constant current; $\mathrm{P}=$ constant power. All symbols have standard definitions according to model provided in [15], [17].

\section{ACKNOWLEDGMENT}

This work is supported by Engineering and Physical Sciences Research Council (EPSRC) funded project on Multi-Terminal VSC-HVDC Networks: Grid Control (EP/L021463/1).

\section{REFERENCES}

[1] P. Kundur, N. J. Balu, and M. G. Lauby, Power System Stability and Control. New York, USA: McGraw-Hill, 1994.

[2] ENTSO-E, "Establishing Network Code on High Voltage Direct Current Connections and DC Connected Power Park Modules," Technical Report, Brussels, Aug. 2016.

[3] T. M. Haileselassie, R. E. Torres-Olguin, T. K. Vrana, K. Uhlen, and T. Underland, "Main grid frequency support strategy for VSC-HVDC connected wind farm with variable speed wind turbines," in IEEE Trondheim PowerTech, 2011.

[4] T. M. Haileselassie, K. Uhlen, "Primary frequency control of remote grids by multi-terminal HVDC," in IEEE Power and Energy Society General Meeting, 2010.

[5] L. Shen, M. Barnes, R. Preece, J. V. Milanovic, "Frequency stabilization using VSC-HVDC," in IEEE Power and Energy Society General Meeting, 2016.

[6] Y. Pipelzadeh, B. Chaudhuri, and T. C. Green, "Inertial response from remote offshore windfarms connected through VSC-HVDC links: A communication less scheme," in IEEE Power and Energy Society General Meeting, 2012.

[7] J. Zhu, C. D. Booth, G. P. Adam, A. J. Roscoe, C. G. Bright, "Inertia emulation control strategy for VSC-HVDC transmission system," IEEE Trans. Power systems, vol. 28, no. 2, pp. 1277-1287, 2013.

[8] A. Moeini, I. Kamwa, "Analytical concepts for reactive power based primary frequency control in power systems," IEEE Trans. Power Systems, vol. 31, no. 6, pp. 4217-4230, Nov. 2016.

[9] M. Farrokhabadi, C. A. Cańizares, and K. Bhattacharya, "Frequency control in isolated/islanded microgrids through voltage regulation," IEEE Trans. Smart Grid, (Early Access), 2016.

[10] L. Harnefors, N. Johansson, and L. Zhang, "Impact of inter-area modes of fast HVDC primary frequency control," IEEE Trans. Power Systems, vol. 32, no. 2, pp. 1350-1358, Mar. 2017.

[11] "Balancing and frequency control: A technical document prepared by the NERC resources subcommittee," NERC, Tech. Rep., NERC, 2011.

12] National Grid, "System Operability Framework 2015," 2015. [Online]. Available:http://www.nationalgrid.com.uk/industryinformation/Futureof-Energy/System-Operability-Framework. [Accessed: 14 Jul. 2016].

[13] J. H. Eto, J. Undrill, P. Mackin, R. Daschmans, B. Williams, B. Haney, et al, "Use of frequency response metrics to assess the planning and operating requirements for reliable integration of variable renewable generation," ERNEST Orlando Lawrence Berkeley National Laboratory, USA, 2010

[14] O. Anaya-Lara, F. Hughes, N. Jenkins, and G. Strbac, "Influence of wind farms on power system dynamic and transient stability," Wind Engineering, vol. 30, no. 2, pp. 107-127, 2006.

[15] DIgSILENTGmbH, "DIgSILENT Power Factory V 15.2-User Manual," DIgSILENTGmbH, 2014.

[16] PPA Energy. Rate Of Change Of Frequency (ROCOF) Final Report 2013.

[17] N. Modi, T. Saha, N. Mithulananthan, "Performance of power oscillation damping controllers with different static load characteristics," in IEEE Power and Energy Society General Meeting, 2011. 